\title{
COGNITION AND SOCIAL INTERPRETATION ${ }^{x}$
}

\author{
JOHN E. BOODIN \\ Carleton College \\ POSTULATES OF THE COGNITIVE PROCESS
}

At the outset of our inquiry it may be well to point out certain general presuppositions that we now recognize as implied in the activity of cognition.

The conative character of the knowing process.-This postulate has to do with the subjective aspect of the process. As over against the sensationalist type of psychology we seem to be pretty well agreed now that the springs of mental activity must be found in instinctive tendency. Our instincts and general tendencies condition our interest and attention; they furnish the fundamental motives of our action. They are, indeed, much enlarged and complicated in the course of experience, but they remain the bearers of the psychological process. In them must be found the basis of individual initiative. They furnish the warp of the social texture of experience. If it is futile, moreover, to try to compound a self out of sensations, it is equally futile to account for it as imitation. There must be selective tendencies as basic motives in assimilating our environment, be it social or physical. Not everything can be reduced to social exchange, because then there would be nothing to socialize. We should be like the two boys of whom their mother boasted that on rainy days they made two dollars a day by staying at home and trading with each other. The social environment can furnish tools, stimuli, mutual supplementation and correction, but the primary basis of interest and action must be found in the instinctive constitution which comes to light through the reaction to stimuli in the developmental process.

The character of recurrence. - The postulate of recurrence has reference to the objective content as the former has to interest.

I Read in part before the Western Philosophical Association, University of Chicago, April 9, I9I4. 
Its importance has been emphasized in some form or other since Plato. It has recently received fresh statement from Poincaré and others. Without some constancy in the midst of the flux of experience, predicates, descriptions, predictions, in short, knowledge, would be impossible. It is true that Bergson has recently revived the ultra-heracleitean doctrine that constancy itself is an illusion, due to the limitation of our experience in following the infinitesimal changes of reality. But this is after all a dogmatic assertion, a passing (by means of a supposed intuition) from the particular premise of empirical experience, which testifies to the reality of change, to the universal that everything is change. Such a universal could never be affirmed in a world having the constitution it predicates, for in such a world no statements could be made, no social rules of action would be possible. As a logical theory the assumption of absolute flux will always be self-contradictory and must be left to those who share the superhuman intuition attributed by Bergson to the hymenoptera. Recurrence, indeed, implies a world of process, but a process in which predicates in the midst of the somehow novel can be singled out as leadings in our reactions to our world.

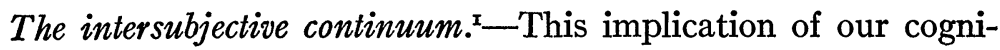
tive experience has been slow to be recognized in logical theory. We have, on the contrary, assumed, tacitly or explicitly, the opposite, viz., that human experience is insulated in individual centers and that the only way we can take account of another mind is by inference from the analogy of bodily behavior. From this absurd assumption of modern psychology there are signs of revolt, particularly in British thought. ${ }^{2}$ The truth seems to be that intersubjective acquaintance is an immediate datum. In the words of Alexander:

The recognition of other beings as conscious subjects depends on a direct experience to that effect. It cannot be regarded as a mere inference from the outward actions, gestures, and speech proceeding from certain bodies, and

For a more extensive argument for the reality of this see the writer's paper, "The Existence of Social Minds," American Journal of Sociology, July, I913, pp. 170-185.

'See particularly Ward, Naturalism and Agnosticism, Vol. II, chaps. xvi, xvii; Taylor, Elements of Metaphysics, Book III, chap. ii; Book IV, chap. iii; Stout, Groundwork of Psychology, pp. I70-87. 
an interpretation of them on the analogy of ourselves. Such interpretation and inference do occur, but only when there has already been a basis of direct experience of others as conscious beings. ${ }^{\mathrm{x}}$

Such immediate recognition can be found already on the instinctive plane. The animal seems to react differently to the animate and the inanimate. This comes out particularly in the instinctive reactions of gregariousness, sex, and rivalry, but every instinct has doubtless its sympathetic inlet for taking account of corresponding attitudes in other animals. It appears on a higher plane wherever purposeful co-operation and division of labor are involved. The common water of experience overflows our artificial measures. This intersubjective character of mind has found a literary champion in Maeterlinck:

It is vain for us to keep watch upon ourselves, to shut ourselves up within ourselves: our consciousness is not water-tight, it escapes, it does not belong to us; and though it requires special circumstances for another to instal himself there and take possession of it, nevertheless it is certain that, in normal life, our spiritual tribunal . . . . is a kind of forum or spiritual market-place, in which the majority who have business there come and go at will, look about them and pick out the truths, in a very different fashion and much more freely than we would have believed.2

The egocentric predicament is the product of our artificial abstraction. In reality experience is social experience, the predicaments are social predicaments. It is through the stress of intersubjective relations, co-operation, and rivalry, whether on the instinctive level or the highly intellectual level, that consciousness rises to the recognition of ego and alter and raises problems. The frank recognition of the immediate character of the intersubjective continuum will rid us of the difficulty of accounting for what the old realism called the transsubjective reference of thought. Such

I Mind, January, I9I3, p. I7. See a paper I read before the American Philosophical Association, I9r2, under the title "Individual and Social Minds," which appeared in the Journal of Philosophy, Psychology, and Scientific Methods, March 27, 1913, and also the paper in the American Journal of Sociology on "The Existence of Social Minds," referred to above. T. Lipp's doctrine of Einfïhlung (empathy or, as McDougall translates it, "sympathetic induction") seems to be in the same direction, though I had not known it. Of course the mystical doctrine of intussusception has always implied direct recognition of intersubjective relation.

${ }^{2}$ The Double Garden, pp. I56, I57. 
reference remains an absolute impossibility if we hold the conception of mind as isolated subjective states. If we start with solipsism, we can never get anything but solipsism.

\section{TYPES OF SOCIAL INTERPRETATION}

In an interesting and suggestive discussion in The Problem of Christianity, ${ }^{,}$Professor Royce distinguishes between three types of knowledge-perception, conception, and interpretation. The first two he conceives as individual processes, using Bergson as the representative of perception and Plato of conception. Interpretation, as opposed to these, he conceives as a social process and in connection with it develops his own theory of the interpreting community and of the universe as a self-interpreting unity in time. But perception and conception, taken from the point of view of the individual, are abstractions. The types of knowledge which Royce has in mind presuppose, at least as known in our human experience, the social consciousness. They are types of social interpretation. They interpenetrate, moreover, in various ways, so that the types mark rather dominant aspects than exclusive categories. We must now restate these types in our own way. If we define judgment as the conscious use of experience in meeting a predicament, practical or theoretical, ${ }^{2}$ then we may, I think, distinguish three types of interpretation-perceptual, conceptual, and mystical.

Perceptual interpretation. ${ }^{3-T h i s ~ t y p e ~ o f ~ i n t e r p r e t a t i o n ~ i n v o l v e s ~}$ the conscious drawing on the concrete associations of the past in the service of some immediate need. It is distinguished from conceptual interpretation by the absence of an articulate plan. We act upon the situation as a whole instead of singling out its relevant features. We confront the emergency. We are perplexed. We strive to reproduce what we have seen others do or what has been told us about such a case and we try to act accordingly. Perceptual interpretation may imply analysis and principles, but these are taken over as the result of concrete imitation of others or

${ }^{x}$ See particularly chaps. xi and xii of Vol. II.

${ }^{2}$ Cf. Bagley, The Educative Process, p. I30.

3 Hobhouse uses the term "practical judgment" for this type of experience; see Mind in Evolution (rgor), chap. vi. 
perhaps as the products of the individual's previous thought. They are not at the time due to the conscious activity of the individual. What $I$ wish to show is that our perceptual interpretation of experience owes its significance in large part to social suggestion. The social matrix of which we are a part dictates to a large extent our emphases throughout our life-history. In the early stages of experience particularly, it is social suggestion which by its selection and repetition of stimuli makes possible that consciousness of recurrence which in the motley, ever-shifting stream of processes of infant life makes certain objects stand out as satisfying definite expectancies. Thus the bottle, with its satisfaction of a primitive need, the objects which minister to the impulse of play, etc., become fixed in the consciousness of the child.

If we take again such an elaborate process as that of the psychologist's introspection, whether under ordinary or experimental conditions, it is easy to see that this is a highly socialized affair. Not only is this true of the conceptual methods he employs, but of the observed data themselves, the things and qualities which he analyzes. It is dangerous to speculate as to what experience is like in animals practically unaffected by intersubjective intercourse. But the sense of qualities here must be fused with the affective and impulsive aspects. They must adhere in one vague disposition. This is not subjective, as is sometimes mistakenly supposed. For it the cleavage of subjective and objective has not arisen. Fact and value are not at strife. Even in higher animals, like the dog, where the intersubjective consciousness plays a considerable part, the qualities exist only as parts of dispositions to actions, submerged in the satisfactions which the dog seeks. The same must be largely true on the most primitive level in human experience, whether in the child or in the race. The satisfaction of curiosity, so far as we call that "disinterested," must in the more primitive experience be auxiliary to, and submerged in, the more pressing instincts of fear and self-assertion. Hence it is that the religious sentiment, with its intensely practical implications, develops so early in human experience.

The interpretation of things and their values must of course begin long before we realize what we are about, before we are 
self-conscious. Subtle suggestions by gesture and action first serve to guide us in learning the uses of things. In the words of Ames: "The only way in which objects come to have significance for us is in reference to our conduct, and that conduct is social in its nature. . . . The uses of objects, their names, their values, and their properties are designated for us." This is true even of our most primitive needs. Our eating and drinking are socially regulated from the beginning. With the use of names carefully provided for us we learn to individualize things and qualities, with their characteristic satisfactions. Without language the distinctions must be merged in the instinctive uses which they serve, and, even after language has individualized things for us, the use or satisfaction remains a significant factor of the situation. How subtle the intersubjective emphasis and guiding may be was well illustrated a few years ago in the familiar instance of the clever horse, Hans, who had learned to take account of indications quite unbeknown to his master and for a long time to psychological experts, and who was thought for a time to possess extraordinary means for reading his masters' mind. In human beings such social rapport must be far more subtle than we realize. Our emphases and evaluations of life are largely based on indications only in part articulated-frowns and smiles, attitudes of behavior, rewards and punishments, approval and disapproval, unnoticed suggestions, particularly effective when there is the consciousness of prestigeall the influences that go to make for us the social atmosphere in which, waking or sleeping, we live. So, before we know it, we have standardized the facts and values of our experience in social terms; and we remain for the most part slaves of those standards except as new intersections of social currents may serve to liberate us for a time. What is sometimes called intuition is shorthand for manifold experiences-impressions, suggestions, judgmentspacked together. Very little of this assimilation is self-conscious and hence the product seems so mysterious. It is the noes and yeses, the emphases, the urgings and inhibitions of all those about us, compounded into our own instinctive nature. To define insight as intuition does not explain, but obscures, the real causes of the process.

I "Social Consciousness and Its Objects," Psychological Bulletin, VIII, 409. 
We have already indicated how essential the process of naming is to the explicit consciousness of distinctions. What a vague world is Helen Keller's before the discovery comes to her that things have names and she becomes a part of the world of conscious intercommunication. "For weeks Miss Sullivan had been spelling words into her hand which Helen Keller had repeated and associated with objects; but she had not yet grasped the idea of language in general, the fact that everything had a name, and that through names she could share her own experiences with others and learn theirs-the idea that there is fellowship in thought. This came quite suddenly," and with it a new joy and a new world. For those of us who have the advantage of the more social senses of sight and hearing, the dawn of this world of intersubjective fellowship came by degrees and is prehistoric; but it is none the less responsible for our sense of community in things and thoughts. It is this need for common action rather than any one group of sensations, such as the touch-motor, that gives us the consciousness of the world "between you and me."

We need only stop to take stock of the objects of perception to find how socialized they are. If we take, for example, the spreading-out of qualities into kinds and the evaluation of them, this is obviously the result of long social elaboration. Berkeley, in his attempt to account for qualities as subjective modifications, neglected the social character of these qualities. This does not mean that the perceptual world, as over against the ideational, is a priori a world common to several observers. We no more have direct guaranty that we have the same sensations than that we have the same ideational processes. That we believe them to be the same in each case is itself the result of social comparison and correction. We can no more say in the case of sensations than in the case of ideas: Here it is, come and see or hear. The person may be color-blind or tone-deaf. Such defects can come to light only with social comparison and serial arrangement. It would have done no good for Dalton to tell his Quaker co-religionists, Come and see, these stockings are black. They saw and were horrified because they saw the stockings as scarlet. By social comparison Dalton thus discovered the phenomenon of color-blindness. A

${ }^{x}$ Cooley, Social Organization, p. 62. 
common perceptual world is the outcome of the socialized process, not the presupposition of it.

The ranking of qualities as primary and secondary is a matter of social convenience. ${ }^{\mathrm{x}}$ To be sure, the qualities that have traditionally been regarded as primary are least capable of social elaboration. The senses that furnish the greatest opportunity for social communication are sight and sound; and yet colors and tones have not been included in the traditional list. But this list is biased by the importance which the physical sciences have attached to the mechanical qualities. Such an emphasis is unknown to the animal and to the primitive man. If the dog had a primary list it would probably be in terms of smell, as he relies for the most part on this sense for identification. The fact is that the whole distinction between primary and secondary is relative to social purposes and varies with those purposes. It would be different for art from that of mechanical science. Even in scientific description the convenience which qualities serve for purposes of identification varies vastly as between different sciences. Botany and anthropology have a different list from physics.

It is true, however, that while the tactual-motor qualities furnish a very narrow world so far as social communication is concerned, they give us a first-hand acquaintance with material things -resistance and space occupancy-which cannot be furnished by any other sense. It is because of the important rôle which material things have played in the socializing process of the race as instruments for satisfying man's primitive needs that commonsense came to assume that, while other senses might give us more varied and more extensive information of the world in space, yet "touching is the real thing." Carlisle is only giving emphasis to this verdict of common-sense when he says: "It is in this capability of being passed from hand to hand that both 'objectivity' and identity primarily exist." "How do we prove that any appearance corresponds to reality? .... There is, we can say to our neighbors, 'Come and feel and handle this alleged thing álso, and tell us how it presents itself to you.",", But this already

${ }^{r}$ See "Knowing Things," Phil. Rev., XX, 386-404.

${ }^{2}$ Mind, N.S., XXXVII, $5^{\text {I2. }}$

3 Ibid., 5 I7. 
presupposes the conception of things with names and the ranking of qualities. In the psychological genesis of things the use or satisfaction must have been of primary importance. In the primitive instinct for food, if sight or smell is instrumental to handling, so is handling to eating. The emphasis of the tactual-motor qualities must itself have been the result of the process of social differentiation in the service of practical satisfaction. Empedocles is nearer the primitive consciousness when he insists that we must give equal weight to the evidence of all the senses. They are all equally instrumental at the outset.

Bergson has taken his cue from our highly abstract physical sciences in his thesis that the intellect is fashioned on matter and for matter. This seems plausible enough if you rely, as he chooses to do, on uncritical intuition. There is evidently a striking fitness between our intellectual ideal and what we conceive as matter. As an account of genesis, however, Bergson has exactly reversed the process. So far from the intellect being molded on matter, the latter owes its definiteness and simplicity to the logical laws of the intellect and our need for common plans of action. The intellect has created the limit of the rigid solid because in this way it could describe most economically certain phenomena of the physical world. It would be wrong, however, to suppose that the intellect first discovered law and uniformity by impinging upon solid things. It was from the stern school of custom with its impersonal and effective enforcements that men first learned the meaning of regularity and necessity. The physical world was for ages interpreted as an extension of the social order of wills. It was to be controlled by sacrifices; and at best it seemed a freakish and incalculable sort of world. Witness the terror of the sea for the Homeric age. It is only a comparatively modern civilization, with its training in abstractions and tools, which substitutes mechanical sequences and mathematical equations for the earlier anthropopathic conceptions. Each generation, however, continues to go to school to the social order before it has any conception of law in nature.

The emancipation of the instinct of curiosity from its subservience to other instincts, more practical in the immediate struggle 
of existence, is itself a highly interesting result of civilization with the security and leisure which it brings. Truth meant originally what was conceived as bringing satisfaction, however absurd the belief might otherwise be. For primitive man to keep peace in an anthropomorphic way with the powers of nature was most intensely practical. The strange was the awe-inspiring. While the element of companionship was not absent, the gods were worshiped mostly for their use in the direct conflict with nature and with other tribes. Three-fourths of the Vedic hymns are to the rain-god, Indra; and Yahweh is originally a fierce war-god. The importance of the proper method of dealing with the mysterious powers made the tribe exceedingly careful about the performance of religious customs; and these again served to strengthen the power of all other customs of the tribe. Inventiveness, however, was not absent on the primitive plane of society. The discovery of the fundamental tools of civilization - the bow and arrow, the ax and hammer-the singling-out from the jungle of experience the categories of thing and quality, of space and time, of cause and substance, mark epochs in human evolution, however slow the process and nameless the inventors. It was by such means that men rose to the freedom to play with nature, to seek to discover its properties and laws-just to satisfy the curiosity of seeing the wheels go round; and then the test of truth came to mean agreement with reality instead of practical satisfaction.

What we call perception, then, is shot through and through with conceptual distinctions. It is highly conventionalized. From those about us we assimilate, without thought, the fruits of centuries of discovery as to the names and uses of things. When we perceive an inch, or a minute, or a chemical element, what centuries of socialized experience is implied in those perceptual judgments; for perceptions as we come to know them in our experience are judgments, they are conscious. meaningful reactions. And so, previous to abstract thought on the part of the individual, he comes to assimilate social thought with its named things, its standardized qualities-conventionalized shapes, sizes, colors, etc. - and its conventionalized relations in terms of yard-sticks and clocks. What becomes difficult for us is, not to perceive things 
in the customary ways, but to recover the innocence of the senses so as to take account of the perceptual objects as they really appear. The old controversy between Reid and Hamilton is thus seen to be based upon a false psychological abstraction. For Reid, "when ten men look at the sun or moon, they all see the same individual object." For Hamilton, "the truth is that each of these persons sees a different object." The solution of the dilemma is that we do not perceive physical objects as though we were passive mirrors. Neither do we, except as psychologists, take account of the psychological processes by means of which we become aware of objects. What we perceive is the standardized object with a name and with its social uses.

Nowhere is this socializing process more evident than in the traditional statement of the categories. For Kant such general categories as space, time, cause, and substance are assumed as a priori. Kant is able to extract directly out of his intuition the axioms of Euclidian space and of serial time, the categories of cause and effect and of substance. While it is true that the organism through long ages is at home in the world of space and time, is predisposed to react in certain ways, it is clear to all of us now that the categories as we have them-the postulates of a common space and a common time, with their artificial measures; of the invariable sequence of phenomena; of constants in the midst of the flux-have come to exist in the service of social prediction and are the results of ages of social analysis and elaboration. Kant did get them out of his intuition, as every mature person growing up in a complex society will always discover them, but he only got them there because they had been packed in by social suggestion before he realized that he had them.

It seems evident, then, that our perception of things, their qualities and their arrangement, is not an affair of abstract individual psychology, as it has ordinarily been studied, but a highly socialized affair, the result of our first having assimilated secondhand the social discriminations and elaborations of ages, under the pressure and guidance of our social environment.

We have so far illustrated the social character of perceptual interpretation in terms of our physical world. We might with

${ }^{x}$ Ward, Naturalism and Agnosticism, p. $\mathbf{1 6 5}$. 
even more advantage have used our social perceptions. Our social judgments are for the most part unreasoned - the result of the condensation of our past experiences and the assimilation of the experience of the race. That we treat human beings as familiar or strange, as reliable or unreliable, as friends or enemies, as good, bad, or indifferent; that we behave toward one social group in one way and to another group in another way, that we act differently in church from what we do at the club, at home from what we act abroad-all this intricate, subtle, and varying response to our complex social environment is indeed a matter of interpretation, but it only seldom comes within the light of reason. The appearance of rationality comes from the fact that we have assimilated the conventional axioms, and the cumulative customs of society, the social heritage. In the words of James:

As a matter of fact we find ourselves believing, we hardly know how or why. Mr. Balfour gives the name of "authority" to all those influences, born of the intellectual climate, that make hypotheses impossible or possible for us, alive or dead. Here in this room we all of us believe in molecules and the conservation of energy, in democracy and necessary progress, in Protestant Christianity, and the beauty of fighting for the doctrine of the immortal Monroe, all for no reasons worthy the name. We see into these matters with no more inner clearness, and probably with much less, than any disbeliever in them might possess. His unconventionality would probably have some grounds to show for its conclusions; but for us, not insight, but the prestige of the opinions is what makes the spark shoot from them and light up our sleeping magazines of faith. Our reason is quite satisfied, in nine hundred and ninety-nine cases of every thousand of us, if it can find a few arguments that will do to recite in case our credulity is criticized by someone else. Our faith is someone else's faith, and in the greatest matters this is most the case. ${ }^{\mathrm{I}}$

Whether the prestige of these social axioms is due to our loyalty to the customs of a hoary past, or to the impressiveness of great contemporary leaders, or to the tyranny of majorities which carry us by their very mass, it is true that our social judgments are for the most part unreasoned-the condensation of social suggestion. Borne on the crest of the historic stream of interpretation, we are able to raise our heads for a moment, now and then, so as to do a little surveying for ourselves. But by an ever-acting law of psychological gravitation we tend ever to sink to the level of practical routine.

\footnotetext{
× The Will to Believe and Other Essays, p. 9.
} 
Conceptual interpretation.-Conceptual judgment is a wideawake, self-conscious use of experience in the service of the problems which we must meet. Instead of dealing with experience in the concrete, we seize upon the features of the situation which are relevant for the special purpose. James has wisely said: "There is no property absolutely essential to any one thing. The same property which figures as the essence of a thing on one occasion becomes a very inessential feature upon another. . . . . My thinking is first and last for the sake of my doing and I can do only one thing at a time." "The only meaning of essence is teleological, and classification and conception are purely teleological weapons of the mind." ${ }_{2}$ Instead of relying upon concrete association, the mind, "running back and forth like spiders on the web they weave," seeks to discover the identical elements which will enable us to pass from one fact to another and thus find our way in the labyrinth of experience. James makes the "ability to deal with novel data the technical differentia of reasoning." "An empirical or 'rule of thumb' thinker can deduce nothing from the data with whose behavior and associates in the concrete he is unfamiliar." Novelty, however, is incidental. It furnishes the spur in the way of perplexity and doubt. It sets us a problem. What conceptual judgment strives to do is to reduce our situations to types by singling out and abstracting those common features that will enable us to predict and meet such situations in whatever variety and at whatever time they may occur. It liberates us from immediate needs and helps us to prepare for the remote. At any rate it provides us with the tools or principles for dealing with the remote when it comes. It economizes vastly the learning process by substituting the abstract for the mass of concrete facts. To quote James again: "Reasoning may be defined as the substitution of parts and their implications and consequences for wholes." 4

In taking account of this self-conscious process of conceiving the world, this active sorting of experience into its proper pigeonholes and the fixing of labels for these, there ought to be no difficulty in realizing the social dependence of the cognitive process. While

I Principles of Psychology, II, 333.
${ }^{2}$ Ibid., p. 335 .
3 Ibid., p. 330.
4 Loc. cit. 
the non-social animal may build up vague perceptual dispositions which serve its simple requirements of reaction, there is no possibility of conscious definition without membership in the social community with its heritage of tools, of language, and of abstractions. The purpose which leads to description and definition must be a social purpose, the outgrowth of common situations and common needs. Man in his solitude would not invent concepts. James, to whose psychology of the conceptual process we owe so much, seems after all to have looked upon it largely in a solipsistic way. What he emphasizes is that there must be identity within the stream of individual history: "The same matters can be thought of in successive portions of the mental stream, and some of these portions can know that they mean the same matters that the others portions meant." But we should never have risen to this introspective consciousness of identity within the individual stream if we had not first been obliged to recognize that our social fellows can intend the same situations as we do and can remember and hope as we can. James had indeed a clear grasp of the functional character of the concept: "The whole function of conceiving, of fixing, and holding fast to meanings, has no significance apart from the fact that the conceiver is a creature with partial purposes and private ends." ${ }_{2}$ But he shows also that he had not yet liberated himself from the old solipsistic psychology in making the concept the function of "private ends." While the springs for action must be found in individual human nature, it is because we have social instincts and common needs that we strive to understand each other and co-operate in a common task. Our concepts are both the results and the tools of such co-operation.

Not that the characteristic individual reaction can be neglected, but the individual constitution with its tendencies must be translated into the communicable forms of society in order that it may become conscious of its meaning and value. No one realized this better than Plato who has become the chief sponsor for conceptualism. Plato finds the dialogue, the stress of conversation, of social response and correction, the indispensable method of developing concepts. It is here that he differs so vastly from his predeces-

'Principles of Psychology, I, 459.

${ }^{2}$ Op. cit., p. 482. 
sors, the Sophists, as well as the earlier physicists. For them the conceptual process was a means to a concrete end-the mastery of particular situations and the securing of the satisfactions that such mastery brings. If the Sophists were accused of making the worse appear the better reason, it was because the reason did not interest them except in securing the particular end, the winning of the decision of the court or of popular favor. Even for Socrates, the father of the concept, the interest in the concept was concrete. Good meant for him good for something. Conceptual definition meant the defining of concrete uses and satisfactions. It is with Plato that the interest in the concept becomes an end in itself. $\mathrm{He}$ is interested not so much in the concepts of things as in concepts themselves, justice and goodness and squareness in the abstract, the concept of the concept. With him philosophic wonder, the disinterested curiosity in the fundamental natures of things, is for the first time a dominant motive. And the essences or characters which the conceptual process singles out are no subjective abstractions for Plato. They are the essential extracts, the defining principles of reality, which seem to him far more real than its motley flux. On such principles, such insight into the universal uses of things, social action must be based, whether in governing the state or in dealing with nature. The abstract concept is for Plato only more ultimately practical for being abstract and universal, for its emancipation from particular needs. Hence the true statesman must be a philosopher.

The danger of conceptualism lies not in the process itself. This is essential to human progress, the supreme method of man in mastering his world. The danger lies in human laziness-the tendency to routine, to substitute words and formulae for firsthand acquaintance. This is indeed a vice, not of Plato, but rather of his mediocre imitators in all ages. When the interest in the conceptual essences becomes dogmatic and when the human roots and uses of the concept are neglected; when we forget that concepts are but abstractions for the leading of the mind in its control and understanding of that concrete world from which they are wrested; and when the mind is lulled to sleep by the sonorousness of its linguistic substitutes which have now become ends in themselves, 
then the concept becomes the means, not of social mastery and progress, but of social stagnation. Hence there is need of a fresh humanistic awakening - the call to first insights, the realization that concepts are tools relative to social needs-substitutions only for a relative purpose, but not substitutes for reality. Essential they are for our living, but only for the sake of the purpose which created them and which must ever revise and correct them in the cumulative experience of the race. What they leave out may indeed be the more essential for concrete living. This furnishes the end for which they exist and in the service of which the abstractions are made. Hence the lazy giant of society must continually be aroused from its dogmatic slumbers by the pain and travail of fresh adjustments, the rebirth into larger and more adequate conceptions of the life-process. Conceptual interpretation owes its efficiency to its abstractness, but we must ever be on the alert lest the larger prize of meaning and value is lost sight of. When the concepts become masters instead of servants of the social process they defeat their end, and genuine living and progress become possible again only when the social life-process awakens to its own and realizes anew that the Sabbath was made for man and not man for the Sabbath.

In science, as an institution, we have a splendid illustration of conceptual interpretation and the division of labor consequent on our co-operation in an interpretative task. In the early development of science, work is largely individual and discovery is largely a matter of chance. The great Greek scientists, such as Democritus and Aristotle, aimed to cover the whole field of scientific investigation and to correlate the results into a philosophic system. There was, indeed, a sense of dependence upon the past, the appropriation and criticism of the results of predecessors. This accounts for the rapid cumulative progress from Thales to Aristotle. There was, too, a certain amount of contemporary co-operation where a teacher surrounded himself with associates, as in the schools at Miletus and Elea and in the still closer affiliation within the Pythagorean community. But at best there was but little conception of division of labor, each man holding himself responsible for the whole of knowledge. The same is true in early 
modern science. The brilliant discoveries by Copernicus, Galileo, and others were primarily individual enterprises. Francis Bacon's contribution to science lies largely in his ambition to develop a definite technique which would make possible division of labor and systematic discovery. Says Bacon: "Though it may happen once or twice that someone by chance hits upon what has hitherto escaped him, while making effort in the inquiry, yet without doubt the contrary will happen in the long run. For chance works rarely and tardily and without order, but art constantly, rapidly, and in an orderly manner." In the Novum Organum Bacon tried to formulate the methods of scientific procedure. The technique he suggests is neither very original nor thorough; and his dream that discovery would now become a mechanical affair was very much mistaken. Though we formulate all sorts of rules and cautions, yet creative imagination will always be indispensable to scientific investigation. Data accumulated mechanically without reference to a definite hypothesis are, as Karl Pearson has recently pointed out, largely useless. But, while constructive imagination is as important as ever, the rapid advance in modern science is due in no small part to the fact that a universal technique has been developed and that the problem has been divided again and again as a result of increasing specialization. Our modern means of communication which have made it possible for men in distant parts to work at the same problem and to criticize and corroborate each other's results have greatly stimulated the consciousness of a common task. In the course of a comparatively short time, the increasing division of labor and the rapidly cumulative results from generation to generation have made possible systematic discovery of just the kind that Bacon had in mind. While chance, in the way of individual surprises, such as the discovery of the radioactive elements, still plays an important part in the development of science, it is true that the problems are becoming more clearly defined and that discovery is often mathematically foreshadowed, as is instanced in the discovery of Neptune and some of the elements in the natural series of chemistry. While we may agree with C. S. Peirce that the rapid progress of modern science points to an attuning of the human mind to the universe-hints at the orderly 
character of the world of which mind is a part-it is the development of a universal scientific technique and the consequent possibility of mutual supplementation, criticism, and division of labor which marks the difference between the rate of progress in modern as contrasted with ancient science.

Science, however, like every institution, runs the danger of defeating its own end by becoming the victim of its own complex machinery. We can hardly speak with Royce of a community of science. The individual scientist, like the worker in the factory, has become part of a whole so intricate that sympathetic understanding becomes increasingly impossible. Not only are men blinded by their own interest to the significance of problems remote from their own-the physicists to the interests of the recent social sciences-but it is humanly impossible for one mind to attain mastery of the whole. The consciousness of co-operation is more and more limited to the specialists of a small field. The knowledge and appreciation of the vast outlying region is at best largely second hand and conventional.

Were the unity of science conditioned upon the sympathetic unity and mutual understanding of an interpreting community, then science would indeed be a self-defeating enterprise. We should have the paradox that the greater the growth of science, the nearer its dissolution. In the early history of science the unity of apperception was at its height, whether the task was an individual venture or that of a small group who severally and collectively attempted the universe. But if the unity of the interpretant was at a maximum, the unity of the content of science was at a minimum. With the growth and division of the content, a community of interest becomes seemingly impossible. And yet the unification of knowledge must be effected, if at all, by human interpretation. We do not have recourse to an absolute interpreter. The ideal of science remains as ever the making clear and distinct of the entire object of human knowledge. Science, like the recent fashions in woman's dress, must cover everything and conceal nothing.

Fortunately we are not dependent upon the finite capacity of the interpreting mind for the unity of science. There is a dialectic 
within the content of science itself which makes it impossible to chop up the object of science arbitrarily by our limited interests. It is the coherency of the content which compels coherency of interpretation. It is found that our problems overlap in spite of our subjective demarkation; and, therefore, in order to comprehend our special domains themselves, it becomes necessary to take account of their overlapping. To understand physics and chemistry we must understand physical chemistry; and the more concrete our content, the more complex are these interrelations of the sciences seen to be. This new supplementation promises in a measure to remedy the necessary limitations of specialization. Thus specialization comes to the rescue of specialization by virtue of the impersonal dialectic of the content of knowledge.

Some problems, moreover, are common to the various special fields with their subjective demarkation. These problems consist, in part, of the need for the criticism of the general methods of science and the bringing into clear consciousness the nature and test of truth; in part they consist of those common features of the content of the sciences which lie outside the interest of the special investigator. To bring these problems into clear relief and thus supplement and interpret the work of the specialist is the task of philosophy, which in turn has its cumulative unity of supplementation and criticism. When now and then some great scientific genius like Poincare possesses also the philosophic consciousness and translates a vast content into the vernacular of the philosopher, this very much facilitates the systematic survey at which philosophy aims. Thus the historic process of knowledge by its very specialization, and guided by the orderliness of the content of knowledge, seems to forestall the tragedy of the world of knowledge breaking into fragments by virtue of the limitation of interest and capacity on the part of the individual human interpreter. A growing correlation there is in the world of science, but this is due to our growing consciousness of cosmic unity, which shows its sublimity by its very outstripping of our apperceptive unity as interpreters. We can no longer say with the confidence of Kant: We make the unity of nature. Our rôle is not to create but to discover, though we must create the means for discovery. 
Mystical interpretation.-I shall call the larger and more concrete realization of meaning mystical interpretation. Mysticism, as I conceive it, is not opposed to knowledge or exclusive of it, but is a genuine type of cognition. It is not the bog or darkness at the end of the logical process, but an essential element in full-blown knowledge. The cognitive process, whether as conventionalized perceptual interpretation or as abstract conceptual interpretation, seizes upon an edge, an aspect of reality, which is held in the focus for the guidance of some concrete interest. But the focal part of experience, important though it be for logically defining the process-for indicating its set or trend-is an almost infinitesimal portion of the mental situation. It is the myriad unnoticed factors of the fringe which furnish the meaning and value of the abstract focal part. They constitute the sense of the more, of which the focal present is a sign - the more of the perceived, or conceived, or appreciated-which gives reality to the process, and toward which the abstractions in the light of consciousness crowd as Charon's ghosts crowd to the blood of the sacrifices. They furnish the interest and motive for which our focal abstractions exist. It is the marginal field which is responsible for the persuasiveness or inhibition of the context which is attended to. It is this which makes us mean more than we know and whose penumbral leading is brought to light in the stress of the give-and-take process of social dialectic. In the mystical consciousness this more looms peculiarly large and vivid and the edge in the focus becomes correspondingly symbolic. The masses of undated and inchoate associations in the margin here give us the fascination of novel insight, the feeling of hidden recesses, the opening-up of strange, yet welcome, perspectives. By mystical interpretation I mean, then, this peculiar sense of enlargement in the way of meaning and value, of concreteness and individuality, of interpenetration and fluency, where the focal content fuses with the massed fields of ideas and sentiments of the marginal and subconscious reaches. This general significance of mysticism in human experience has been exquisitely stated in the literary language of Maeterlinck:

In Sigfrid's life it is not the moment when he forges the prodigious sword that is most important, or when he kills the dragon and compels the gods from 
his path, or even the dazzling second when he encounters love on the flaming mountain, but indeed the brief instant wrested from the eternal decrees, the little childish gesture when one of his hands, red with the blood of his mysterious victim, having chanced to draw near his lips, his eyes and ears are suddenly opened: he understands the hidden language of all that surrounds him, detects the treachery of the dwarf who represents the powers of evil, and learns to do in a flash that which had to be done.

Whether this concrete and novel insight comes in a flash or dawns by gradual processes, it constitutes the essence of mysticism.

Mystical interpretation is immediate only in the sense that we are unconscious of articulate steps because of the completeness of the fusion of the various fields involved. By reflection we can, often at least, analyze the salient features that go to make the fusion. It differs from what Baldwin calls the primitive immediate-the immediacy of sensations and affective elements -in that it is an immediacy of meaning, not an immediacy of presentation.

The strangeness or novelty which has been emphasized so often as characteristic of the mystical experience is due to the absence of dating, on the one hand, and to the interpenetration and blending of the marginal fields of meaning, on the other. Reverie, indeed, presents a similar character of novelty, but the fringe of meaning is here relatively simple and the associated constellations relatively distinct. In the conceptual type of process the object or focus looms large and the fringe or meaning is merely instrumental in the control of the process. In the mystical consciousness, on the other hand, the object is felt to be a mere passive symbol for the sake of the intimate and living fringe which loses itself in the inchoate recesses of the subconscious where the finite often seems to merge in the infinite. Whether trailing clouds of glory or of dark foreboding, insight is here suffused with a strong affective color. This marked value character of the mystic states, on the one hand, and their fluent character, on the other, have made us for the most part oblivious to the important cognitive implication of such states. To those, however, who have had a vivid realization of this mystical meaning, our abstract knowledge seems a mere shadow and symbol:

Alles Vergängliche,

Ist nur ein Gleichniss; 
Das Unzulängliche

Hier wird's Ereigniss;

Das Unbeschreibliche

Hier ist es gethan.

This mystic enlargement or supplementation of meaning may exist on any level of intellectual unification. It may come with our perceptual synthesis. It may be a vivid sense of value and reality that attaches to our abstract concepts. It may come with emotional types of unity-the ruling passion which unifies not only the novel, but also concrete human lives; which selects the germane and rejects the irrelevant as strictly as a logical principle, but which has been neglected in our abstract treatment of the mind. In its most typical form it is the enlargement of our ideal activity, the sense of the reality of ideal unity and wholeness, of the real presence of what the intellect regards in the abstract. Such an insight it was which filled Plato with wonder and rapturous contemplation and became for him the real motive of philosophy, and which with the absolute idealist and the religious mystic gives rise to the feeling that our experience is but a fragment of a larger whole which envelops us. When it comes to us on the perceptual level it is sometimes called naturalistic mysticism. It seems higher when it inspires us with the sense of ideal wholeness, but the psychological fact is in any case the same, the feeling of living enhancement, a sense of "lurking universality, the adumbration of greater things."

Wherever we find it, analysis will show that condensed social suggestion furnishes the content. We may note this even on the perceptual level. A year ago last spring I walked in from Cambridge to the Boston Public Gardens. Everything was green and in bloom after the dreary winter. I was filled with an indescribable delight. On reflecting upon it, there came back to me the tremendous significance which spring, after the long winter and the long nights, had for us in my ancestral home in Sweden, where I was a child. It was this which lived in me and came back. A little later I passed the Christ Church cemetery and saw the wind sweep over the grass and felt a similar exhilaration. There

I Richardson Hovey's introduction to his edition of the Plays of Maeterlinck, p. 5 . 
were of course the movement and the shifting of light and shade, but these would not have been enough. There was somehow the dim recollection of childhood when waving grass and fields of grain meant a hard-earned victory over parsimonious nature and the prospect of comfort and well-being. This same feeling comes to me whenever I see a wind-swept field of grass or grain. The joy in the babbling brook in a similar way reinstates for me intense childhood experience. The exhilaration $I$ feel in a storm at sea is harder to account for unless one admits ancestral recollection. My ancestors were doubtless daring seamen. It may, however, be only a sharing of the temperament which made the storm a thing of joy to them. Maeterlinck has evidently a strong sense for perceptual mysticism: "There is nothing that is puerile in nature; and he who becomes impassioned of a flower, a blade of grass, a butterfly's wing, a nest, a shell, wraps his passion around a small thing that always contains a great truth." The mystical thrills that came to primitive man in his perceptual converse with nature, before he became case-hardened by abstraction, are evident from the myths, epics, and hymns that have come down to us and not least from our Teutonic ancestors who have given us the Norse sagas and the Niebelungenlied.

Not only was this sense of mystery felt by early man in his converse with nature, but also, and first of all, in his converse with his fellow-men and in the human phenomena of life and death. He had not yet built up abstractions between the individual and the species as we have. Rather was his feeling for life that of "participation." The species, the ancestral totem, lived in the individuals and they in it and the participation could be constantly renewed in the sacramental sharing of the blood of the ancestor. This sense of participation remains in a weakened idealized form in the mystical consciousness that He lives in us and we in Him. If we could live ourselves into this early spirit of participation we should better understand the sense of community life in the bee with its division of labor and the sacrifice of the individual for the race. We should also understand better that living intersubjective continuum which moves and controls in all of us.

× The Double Garden, chapter on "Chrysanthemums," p. 245. 
It has long been recognized that the life of conceptual generalization with its verbal counters is hostile to our concrete sense of meaning and reality. It is this atrophy of the sense of immediate meaning which Darwin feels as a tragedy in his old age, efficient as was the conceptual machine which his intellect had built. $\mathrm{He}$ could no longer enjoy poetry and music, the vehicles of perceptual intuition; and he felt that his moral sense, too, must have been calloused by this phobia of abstraction. It is this artificializing of life which makes us lose the sense of social mystery until even Maeterlinck, the mystic, complains that we "cannot even, without the mightiest difficulty, avail ourselves of it [the terrible unknown], though in all loyalty, to raise to the point of mystery the gestures, actions, and words of the men we pass every day." This lack, except under extraordinary circumstances, of the sense of reality of the inner life of our fellow-men and of its interpenetration with ours is a genuine loss and shows how dearly bought are the victories of abstract civilization. It does, however, come back under the stress of emotion, particularly in love and in religious emotion. It is this sense of mystery, of unexpressed meaning, which accounts for the comfort and value we find in our religious formulae, when intellectually they either have ceased to mean anything to us; or, if reflected upon, seem contradictory and abhorrent. They have become mere symbols for the living spiritual community of a subtle growing meaning which the words serve to suggest.

It is in the larger ideal perspectives of meaning, with their categories of consistency, unity, economy, and harmony, that the great scientific mind and the Christian religious mystic alike feel the sense of enlargement which outstrips our conceptual divisions. These ideal tendencies have their root in our instinctive nature, though they only gradually come to consciousness in our experience. I agree with Maeterlinck as to the fundamental claims of our ideal tendencies:

It is fitting that we should come to an understanding, once for all, on the rights of our instincts. We no longer allow the rights of any of our lower instincts to be contested. We know how to justify and to ennoble them by attaching them to some great law of nature. Why should not certain more elevated instincts, quite as incontestable as those which crawl at the bottom

${ }^{3}$ Maeterlinck, The Double Garden, p. I24. 
of our senses, enjoy the same prerogatives ? Must they be denied, suspected, or treated as illusions because they are not related to the two or three primitive necessities of animal life? Once that they exist, is it not probable that they are as indispensable as the others to the accomplishment of a destiny concerning which we do not know what is useful or useless to it, seeing that we do not know its objects ?

I have argued long ago for the instinctive basis of the ideal tendencies; but I would go farther than Maeterlinck in holding that in the realizing of these tendencies in terms of our experience we are also gaining insight into the object toward which they aim. They are indeed homing instincts, indicating our highest human vocation and the constitution of the universe of which we are a part. As the birds are moved irresistibly by the spring winds to seek the northern climates, and as the bees build their intricate homes for a future they shall not see, not knowing what they are doing, so the human mind in a social world of stress and strain is awakened to the longing for the ideal-the complete knowledge, the vision of God, the life of beauty and holiness, pushed on step by step, through mistakes and errors, to the realization of its immanent destiny. "He guides me and the bird." It is through the dialectic of social experience, as Plato so clearly saw, that we become conscious of these ideal tendencies and their implications. For the abstract intellect they are, indeed, limits. But it is not as logical limits or abstract unmoved movers that they motivate conduct, draw us onward, but as parts of our instinctive nature. This, indeed, Plato realized in his half-mythical theory of recollection, as he also realized the mystic glow which abandon to their leading furnishes the soul as it mounts to the absolute beauty, "which without diminution and without increase, or any change, is imparted to the ever-growing and perishing beauty of all other things."

But not only a poet and a philosophic dreamer have felt the mystery and poetic zest of the quest for truth. One of the greatest of scientists kept alive his sense for first things. Says Poincaré:

The scientist does not study nature because it is useful; he studies it because he delights in it, and he delights in it because it is beautiful. If

I The Measure of the Hours, p. I3I. I have argued for the instinctive character of our higher categories in an article, "Mind as Instinct," published in the Psychological Review, 1906, since reprinted in Truth and Reality" (Macmillan, I9rI).

${ }^{2}$ The Symposium, § $2 \mathrm{Ir}$. 
nature were not beautiful, it would not be worth knowing, and if nature were not worth knowing, life would not be worth living. . . . . I mean that profounder beauty which comes from the harmonious order of the parts and which a pure intelligence can grasp. . . . . It is, therefore, the quest of this especial beauty, the sense of the harmony of the cosmos, which makes us choose the facts most fitting to contribute to this harmony, just as the artist chooses from among the features of his model those which perfect the figure and give it character and life. And we need not fear that this instinctive and unavowed prepossession will turn the scientist aside from the search for the true. One may dream a harmonious world, but how far the real world will leave it behind. . . . . And it is because simplicity, because grandeur, is beautiful, that we preferably seek simple facts, sublime facts, that we delight now to follow the majestic course of the stars, now to examine with the microscope that prodigious littleness which is also a grandeur, now to seek in geologic times the traces of a past which attracts because it is far away. We see too that the longing for the beautiful leads us to the same choice as the longing for the useful. And so it is that this economy of thought, this economy of effort, which is, according to Mach, the constant tendency of science, is at the same time a source of beauty and a practical advantage. ... . This intellectual beauty it is which makes intelligence sure and strong. .... But this disinterested quest of the true for its own beauty is sane also, and able to make man better.";

Thus it is written in our instinctive nature and in the fundamental constitution of the universe that we shall work together to become conscious of beauty and to create beauty; and as we so follow the mystic leading of that which is most characteristic of our human nature we shall attain not only beauty, but success, because we shall discover the laws of our world and be adjusted to it.

We have discussed three types of social interpretation: first, perceptual interpretation, the acknowledgment of things or individuals with their qualities, their concrete space and time patterns, and their causal implications; secondly, conceptual interpretation, the sorting of experience into kinds, with their fixed linguistic labels; and finally, mystical interpretation, the sense of enlarged meaning, due to the fluency and blending of the field in attention with the massed fields of association and sentiment of the fringe. The last named we have seen is not peculiar to Bergson and the higher insects, but a normal part of interpretation in its various stages, with its intuitive element of faith and the sense of reality which it implies. But there is, especially on the highest stage,

${ }^{x}$ Value of Science. 
that of ideal interpretation, a peculiar sense of prevision, a feeling for unity and harmony which far outstrips our actual generalizations. This is, indeed, rarely brought into reflective consciousness and when so brought figures as conceptual limits. It is a concrete feeling for unity at each moment of knowledge, a sense of convergence and wholeness, which guides our search for truth. Though the form is finite, yet each moment the sense of convergence, of blending or fusion, has a different significance. As the process itself is a growing process, this ideal can never be realized. The mind somehow throws its shadow ahead, the form dictates to the process, or rather divines, feels into, the beyond toward a complete ideal. This feeling for unity and harmony is not the result of ratiocination, but the living motive of it. It is this idealization of the actual, or, perhaps better, the sense of "the real presence" of the ideal, which constitutes peculiarly the mystic consciousness.

The implicative function within the interpretative process seems to manifest itself differently at different stages of the process. On the perceptual level the implication is longitudinal. It is prospective. If it refers backward to antecedents, to remembered sequences, this is only in the service of the forward look, the adjustment to its world. On the conceptual level, the implication is transverse; it intersects the concrete sequences in all sorts of ways, to establish convenient leadings for action. On the level of ideal mystical interpretation, the reference or implication is circular. Seeking and attainment blend in obedience to a guiding principle into one unity, an individual whole. The guiding principle is here first of. all felt and only secondarily and as an afterthought abstracted into a bloodless logical limit. Perceptual interpretation aims at factual acquaintance and delimitation for immediate action, conceptual interpretation at description and definition for remote action, mystical interpretation at idealization and living communion, where the remote and ideal becomes a living present.

\section{THE UNITY OF THE INTERPRETING PROCESS}

Recent thought has emphasized the unity of the interpreting process. $^{\text {I }}$ Not only has it been shown that the logical concepts

'This idea received its brilliant impetus from James, Principles of Psychology. It has gained new strength from Schiller. But its most thoroughgoing expression is to be found in the Chicago School. 
and categories are for the sake of the fuller life of action and appreciation, but it has been made clear that all the aspects of human nature blend in the cognitive process. The cognitive process is rooted in instinct, the affective and emotional elements are fused in varying degrees with the presentational. There is no such thing as a cognitive faculty, divided off from other compartments of human nature. Even "disinterested" knowledge, the play of curiosity, is rooted in an instinct, has its characteristic satisfaction as part of an organized sentiment, as well as its intellectual character of agreement. In the cognitive situation, therefore, the whole unity of the self is involved, not abstractly merely (ïberhaupt), but as a concrete living process. This process, moreover, is a social process. It is because of intersubjective pressure or problems that the interpretation comes to take place at all. Even when we think in solitude, or "without a fellow," we do so by means of social tools and social distinctions and as part of a social community. It is only thus that self-consciousness can arise. In the words of Taylor: "To realize your own ends, you have to take note of the partly coincident, partly conflicting, ends of your social fellows, precisely as you have to take note of your own. You cannot come to the knowledge of one without coming by the same route and the same degree to the knowledge of the other."

C. S. Peirce and Royce have tried to show that our thinking is triadic. In the language of Peirce, judgment involves presence, reference to a ground and an interpretant idea. These are conceived as external factors. Such distinctions, however, are merely artificial, the product of the particularization and substantiation of language. Whatever convenience such treatment may have for formal logic, it seems to be based upon a faulty psychology. There is nothing in psychological analysis to indicate that when we compare two facts we compare with an image. Rather our interest in comparison is in the concrete relation, from which the terms are intellectual abstractions. The psychological situation in comparison is that of a volitional context of association taking account of a datum. But the datum is not something external to the volitional context. It is a datum because it has been selected

× Elements of Metaphysics, p. 205 . 
by the context. This context, moreover, need not rise to selfconsciousness. It may be of an automatic kind. It always tends to become so with familiarity. Psychologists like Titchener, noting this solidified character of the context, speak of it as a cerebral context. This, however, seems a confusion of terms. Cerebral contexts do not supply meanings, they supply causal reactions. What is shown is that self-consciousness has disappeared with the absence of stress. The context has become organized in terms of its datum. It has a constant set. It meets the situation with facility and precision, instead of with a shock and the need for readjustment.

But whether the context of meaning rises to self-consciousness or not, it is not something over against its terms. The latter are part of its intent or set. It matters not how many terms are implied in the cognitive interest. It may be a single item selected by some need or uneasiness. The cognitive situation, again, may imply an infinite number of terms, or even grades of infinities, as in the number series. But these terms are after all merely abstractions from the interesting relation within which they are comprehended. They do not exist as bare presences, referred to an abstract ground and interpreted by means of an abstract idea which psychology fails to reveal. Nor is the intersubjective relation a term external to the individual situation of interest. But the active interest is a socialized interest, determined in part by the intersection of social currents. Self-interpretation is itself social interpretation, the translating of our needs and tendencies into terms of social standards. Only so can we discover our own meaning and value. Society, in truth, can say: When me you fly, I am the wings. We do not have to do with a socius and a self, pointing to an abstract presence, but with a socialized self-a self transformed and played upon by social suggestion. It is this which constitutes a situation by its selective delineation.

The problem does not differ essentially whether we are dealing with a cold-storage meaning in manuscript, or with our own past meaning, or with a present socius, or with nature. In each case we are part of a community of interpretation which has already standardized our facts and values, which is ever at our elbow 
whispering its judgments in our ear, pulling at our coat-tails when we would depart from the beaten path of custom, even as the force of gravity keeps us to the earth in the physical world. In each case our socialized meaning strives to meet a selected context and is tested in the process. In each case the validity of the cognitive purpose is determined by its success in translating into its intent the selected fact; in meeting the intended situation. It is true that the sympathetic co-operation of a living present meaning greatly facilitates the process of correction and supplementation. It is also true that the verification in question must meet the whole situation so far as it is intended. And since, in the case of another meaning, this must mean sympathetic participation in the meaning, instead of merely external control, the verification must be adequate to the intent; but that does not alter the process of pragmatic verification. In case we are dealing with our own past meaning, a part structure within personal experience, this does not mean that the past remains external to the present purpose. It is part of the present situation just because it is selected. It is no longer an external presence. Nor do we interpret the past to a third external presence, viz., the future, which does not yet exist.

What we are trying to do in every case of interpretation is to bring a dim, inarticulate meaning into explicit consciousness, with its correction and supplementation in terms of the data which such a process implies. In any case, the future, in the sense of a new meaning, with new responsibilities, cannot be addressed. It comes in spite of the present meaning. The intent of truth is always finite, the definition of a definite purpose. That the process which is intended is infinite is due, not to the intent, but to the metaphysical time character of the process itself. ${ }^{x}$ Nor is the past immutable except as we take it in its abstractness. From the point of view of significance, as our past, it is ever taking on new coloring, new meaning and value, from figuring in new contexts. From the point of view of our practical relations, the attitude may even be reversed. The friend who has betrayed us does not figure as a friend in our present context of practical relations. The

'My own theory of time I have expressed in "Time and Reality," Psychol. Rev., Mon. Series, No. 26. See especially chap. iv. 
enemy whom we have forgiven does not figure as an enemy. The past deed has been taken into a new context-revised from the point of view of more comprehensive relationships. The past itself, apart from such relationships, is a mere abstract record. Nature, too, so far as we attempt to know it, is part of our social situation. Our conception of nature is the product of the interpreting community, active in some individual constitution which strives to assimilate and to adjust itself to its object.

If we look at the conditions of the interpreting moment, instead of its living functioning, we shall indeed find a number of variables. Thus the physical situation varies independently of our interest. Stars vanish out of our ken, we know not how. Again our meanings grow though the physical object remains comparatively constant. Both the physical object and the interpreting meaning are subject to variables which we must take into account in order to understand their history and present content. Since humanity is an infinite quantity, the number of individual variables which go to determine, in however an infinitesimal manner, the content and direction of history, is practically infinite. But, however important these conditions-physical, biological, psychological, and institutionalmay be for the causal explanation of our meaning at any time, the interpreting moment itself is a unity, an interesting situation, in which biological causes, social influences, personal feelings function as a living whole in selecting the object; and the object in turn is a significant object only because thus selected.

The pragmatic point of view, therefore, must insist, as it always has, upon the wholeness of the interpreting moment as against all abstract formalism. ${ }^{x}$ So far, again, from the pragmatic point of view being unsocial, one can take stock of the intricate interplay of motives in any interpreting activity only by putting oneself within the stream of social history and its intersubjective relations. That individual thinkers have been neglectful at times of such implications does not alter the responsibility of those to whom the task of carrying the process of interpretation onward has been intrusted. I9II.

'My own type of pragmatism I have stated in Truth and Reality, Macmillan, 
Indeed, the danger may easily become, and has often been, the neglect of the individual contribution to the interpreting process. For after all, the process must run through individual constitutions. The light must be refracted through individual media of instinct and temperament. And if we neglect the individual aspect of the process, we shall not only strike a dead level of conservatism, with no invention or progress, but we shall have nothing to socialize. Hence, as over against abstract universalism, pragmatism as a movement has emphasized the importance of the individual contribution-his transformation of the social heritage in assimilating it. The individual is not a mere mathematical intersection point of social currents, but a constitution of tendencies from which the initiative of the process must in the last analysis proceed. This instinctive constitution must translate the social heritage into terms of itself. The result in every genuine case of interpretation is in part unique - not a mere appropriating of the past. Only so is progress possible, and progress means ever new demands for readjustment with the ever-recurring social tragedy, as society strives to mount on its dead past to higher things.

\section{OBJECTIVITY AND SOCIAL INTERPRETATION}

Intersubjective interpretation does not constitute the objectivity or validity of truth. This must be found in the coherence of our judgments with each other and their termination in the intended object. Intersubjective relations furnish us, on the one hand, an incentive, without which the cognitive process could never rise into clear consciousness; and, on the other hand, they furnish us means for supplementation and correction of our individual data. Error and illusion may be social for the time being, but that does not make them valid. Social interpretation liberates us, indeed, from the egocentric predicament. It makes truth impersonal, the same for all of us. In the words of Alexander: "Intersubjective intercourse does not account for the objectivity of knowledge, it only accounts for its impersonality." It does not constitute the cognitive object, unless this itself be a social meaning; and even then the part-meaning thus selected must be treated as objective

Mind, January, I9I3, p. 23. 
to the meaning which takes account of it and evaluates it; error of interpretation is still possible. We may fail to know what we mean, either in our individual or social capacity. Nothing is more difficult to interpret than present history; and we all know what transmutations take place as each individual and each generation interprets past history.

In nature we seem to have a context which lies beyond our finite social experience. Can this in the last analysis be regarded as constituted by social interpretation? We have already pointed out that Berkeley (in The Principles of Human Knowledge), in his attempt to prove that qualities are relative to perception, neglected the fact that they are not subjective in the sense of individual objects. But does the social consciousness, then, create its object? This seems to be the view advocated by two contemporary thinkers, Ward and Royce. Ward points out that "it is not on the practical or historical side that common knowledge conflicts with individual experience, for there the reference to individual subjects is still present and essential. But intersubjective reference on the individual side leads almost inevitably to the omission of this reference; and so for the living green we have the somber gray and man at least and nature are at strife." This omission, according to Ward, comes about in this wise: "Regarding the sun as independent of $\mathbf{L}$ and $\mathbf{M}$ and $\mathbf{N}$ severally, it concludes that it is and remains an object, independent of all collectively." ${ }_{2}$ We may affirm that the House of Commons is an estate of the realm independent of each individual member, but we cannot therefore draw the conclusion that it might be addressed from the throne though there were no members. Ward's analogy, however, does not seem convincing. It is clear that the House of Commons could not exist apart from social consciousness, since it is a social institution, constituted by a common purpose. But it is not obvious that gravitational relations are so constituted. Ward himself evidently feels that something more is required than our finite social consciousness. "Inter-subjective intercourse secures us against the solipsism into which individual experience by itself might conceivably fall, but it

I Naturalism and Agnosticism, II, I70.

${ }^{2}$ Ibid., p. I7x. 
does not carry us beyond the wider solipsism-if I may so term it -of Kant's consciousness in general." ${ }^{\prime}$ Like Berkeley, therefore, he has recourse to a transcendental consciousness, reaching beyond our experience. He arrives at this by a curious method of abstraction. He insists that as in individual experience every object has a subject and vice versa, so the universal object implies a universal subject. But this leap from the implication of our reflective experience to the nature of the universe is a doubtful analogy. It is merely another way of saying that because we think, therefore the universe as a whole must think, which is an act of faith and not a logical proof. What seems transparent is that our finite social experience cannot account for the objectivity of nature.

Royce, in The Problem of Christianity, takes as his startingpoint the implied reality of the social community and its historic process of interpretation. His emphasis on the reality of the social community is true and profound. The historic world of social institutions is a world constituted by our social purposes-a world ever growing with human experience and productive of fresh surprises, which in turn must be assimilated into the social tissue by fresh acts of interpretation. It is true, too, that the interpreting community, with its individual accretions and discoveries, in its cumulative unity in time, constitutes for us the significance of the world. In infinite ages it may take over the seeming brute world into its meaningful context so as to leave no dark corners, no unexplained residue. But is the interpreting community the whole of reality? Does it constitute the reality of the cosmos? This is what Royce would seem to say: "An interpretation is real only if the interpreting community is real, and is true only if the community reaches its goal. In brief, then, the real world is the community of interpretation. . . . Unless both the interpreter and the community are real, there is no real world." "2 Nature exists only for an interpreter. "The world is the interpretation of the problems which it presents." 3 But who is this interpreter? Here we find the same leap from analogy as in Ward, the same shifting

Naturalism and Agnosticism, II, I97.

2 Ibid., p. 269, 270.

3 Ibid., p. 323. 
from the finite community of interpretation to a universal interpreter, the spirit of the universal community.

You are an example of the principle whose active recognition lies at the basis of my only reasonable view of the universe. As I treat you, so ought I to deal with the universe. As I interpret the universe, so, too, in principle should I interpret you. We have no ground whatever for believing that there is any real world except the ground furnished by experience. . . . . In your ordinary social life, you postulate your fellow-man as the interpreter of the ideas which he awakens in your mind, and which are not your own ideas. The same principle, applied to our social experience of the physical world, determines our ordinary interpretations of nature and guides our natural science. For, as we have seen, the physical world is an object known to the community and through interpretation. ${ }^{\mathrm{x}}$

This argument from analogy seems to be defective. It argues from facts which we recognize to be signs of a living, communicating will to facts where we cannot recognize such a will. Royce does not take into account that the recognition of the existence of another mind must be prior to our interpretation of facts as signs of such a reality. Where we are able to recognize a will, consciously furthering or thwarting our purposes, there we come, indeed, to interpret certain sense data of gesture and speech as signs of that will. The real question, then, is whether we can recognize in nature such a sympathetic will of which its sense facts may be taken as. signs.

Assuming that nothing can exist without an interpreter, we pass easily to the conclusion: "The world is the community. The world contains its own interpreter." ${ }_{2}$ But the inference from the truism that every known object must have an interpreter to the conclusion that no object can exist without an interpreter seems to be a leap of faith and not of logic. The finite historic social process, moreover, is superseded by a transcendental spirit of the community which furnishes its supra-temporal and supra-individual unity. This spirit, while immanent in the historic community and revealed in the infinite process of interpretation, infinitely transcends the historic community. It is both its goal and its perennial reconciliation to the plan of the whole. "In this final union of

× Op. cit., pp. 322-24.

2 Ibid., p. 324 . 
temporal sequence, of the goal that is never attained in time, and of the divine spirit through whom the world is reconciled to itself and to its own purpose, the real community, the true interpretation, the divine interpreter, the plan of salvation-these are expressed." But this only makes it evident that the social consciousness as ordinarily understood does not constitute the cosmos, if that needed to be made evident.

Epistemological idealism, it would seem, can be resolved in spite of its varieties into four basic propositions. In the first place, it is laid down that all facts are data of experience. This is, of course, a truism. A fact is a fact only when it is selected by our interest. It is closely associated, however, with a second proposition which is generally treated as an implication of it, viz., nothing can exist except as a datum of experience. This proposition seems to confuse existence and significance. Objects have significance only as selected by our purposes. But it is not self-evident that selective interest creates the facts. Within our experience, at any rate, objects are prior to our interest in them; and sometimes, at any rate, they seem to pre-exist in patterns to which the category of interest is not applicable, i.e., they do not seem to have meaning on their own account. Epistemological idealism owes a large part of its convincingness to the failure to make clear and distinct the second assumption. The third assumption, viz., that all data of experience exist within a unity of apperception, is, like the first, a truism, since objects become data only when they are selected by an interpreting moment. The fourth proposition may be stated as follows: Since the data of experience exist between you and me and independent of you and me, severally, as finite interpreters, there must be a larger unity of interpretation, including all the data of experience. This larger unity has been conceived either as a single experience, the Absolute, or as a continuous cumulative and in some sense self-transcending community in time. It would be impossible and irrelevant here to unravel all the assumptions implied in this fourth proposition. It presupposes the first three propositions, viz., that all facts are data of experience, that nothing can exist except as a datum of experience, and that all data of

I Naturalism and Agnosticism, II, 378-79. 
experience must exist within a unity of interpretation. And yet the second, crucial assumption would hardly be adopted by any sane man except as supported by a belief in the fourth, that of a larger supporting unity. Even Berkeley, in spite of his paradoxical approach to the problem, did not believe that the stellar world ceases to exist on a cloudy day. He could always fall back on God as a guarantor of the constancy of nature. As an effort to account for the social character of our objects, epistemological idealism is at best a clumsy affair. Here, too, it is circular, since it is the social character of our objects, the testimony of practical experience to the effect that objects exist between you and me, that leads to the assumption of a third unity inclusive of you and me and the object. Apart from the logical incoherence of the idealistic argument, it is certainly far simpler to abandon the false assumption of insulated subjective streams. We shall then need no third entity. The interpreting moment is capable of establishing direct continuities with other subjects; and the community of subjects can share a common world of objects and co-operate in their use and interpretation, whether these objects can be recognized as centers of experience or not. This seems to be as far as our experience carries us, and, whether we would or not, we can use no other.

Nature would seem to be independent, at any rate, of our interpretation. The relativity of the qualities of things to our sense-perception, which has been the stock argument of idealists since Berkeley, does not seem to hold, even though we substitute the community for the individual. The variation of the image with the distance, the variation of the shape with the angle of perspective, the illusion of the stick which appears bent when seen in the water-these appearances are not relative to our senses in any other way than they are to the physical camera. This takes account of them precisely as the organic camera of our vision. They are physical phenomena, i.e., they are objective to the process of social interpretation and must be explained by causes independent of our perceiving them. Kant realized that there must be an objectivity beyond our social experience when we deal with nature, i.e., that experience does not constitute its own data; but as he had been led to believe that the sense qualities are primarily 
subjective modifications and that the categories of the mind are a priori in an arbitrary sense, there was nothing left to indicate the objectivity of nature except the thing-in-itself. His intuition was sound, however, that, whatever nature may be in its own right, it is not constituted by our experience. That sense qualities are subjective modifications and that our biologico-social categories are arbitrary-these are gratuitous and pernicious assumptions. Nature, on the contrary, enters into common dynamic situations with our organism, as things within nature enter into dynamic relations with each other. The qualities of nature are precisely what we must take them, as in these dynamic contexts. Energetically the world is one.

But must we recognize the cosmos as a whole as a unity of interpretation? The institutional facts, the social meanings of custom, science and art, of which we must take account, fall within social schemes which the interpreting community must acknowledge as flesh of its flesh and blood of its blood and with which it has a living, sympathetic continuity. The social facts of which we take account have a prior stamp, a meaningful context of their own, which we must recognize in the process of interpretation. Are the facts of nature at large thus socially prestamped with an absolute stamp of interpretation? Have they a prior locus within an absolute system of significance? Evidently there is a mutual fitness between the knowing mind and the cosmic environment, since they have evolved together. The categorical laws of thought may be assumed to be also the laws of things. The selective process which resulted in what we call mind and cognition is itself a cosmic process. In this sense it must be regarded as intelligent and vastly more intelligent than we creatures of a day. But must we recognize this process as itself a self-conscious cognitive unity?

The fact that the physical scientists are becoming a community, taking cognizance of the past (this was hardly true in the Middle Ages), and mutually correcting and supplementing each other within a more and more complex division of labor, does not prove that the object of science is such a spiritual community, unless we suppose that the community of science constitutes its object; and this would defeat the end of science itself, which is discovery. 
The only answer that can be given to the question raised is a pragmatic one. Nature for us is a spiritual community just in so far as we must take it as such in realizing our own social purposes of truth, right, and beauty. Our present organized insight does not seem to make it possible to recognize nature as a whole as such a unity, though in individual mystic temperaments, such as Wordsworth, sympathetic companionship with nature as a living social presence seems to have been a reality. Perhaps it is our ancestral blindness which debars the rest of us from feeling that way. In the meantime the rest of us are not able to recognize it as such for our practical purposes; and the religious consciousness seems to be better served with a finite presence within nature, as the embodiment of its ideals and as the Great Companion. 